\title{
Hear My Song: Teaching Persons with Dementia to Play Musical Instruments
}

\author{
Cameron $\mathrm{J} \mathrm{Camp}^{1^{*}}$, Michelle Bourgeois ${ }^{2}$, Brello $\mathrm{J}^{3}$, Bescan $\mathrm{K}^{4}$ and Bescan $\mathrm{E}^{5}$ \\ ${ }^{1}$ Center for Applied Research in Dementia, USA \\ ${ }^{2}$ University of South Florida, USA \\ ${ }^{3}$ Ohio State University, Columbus, USA \\ ${ }^{4}$ Lakewood Schools, Lakewood, USA \\ ${ }^{5}$ Constellation Schools, Cleveland, USA
}

*Corresponding author: Cameron J Camp, Center for Applied Research in Dementia, Solon, USA, Tel: 4408294927; E-mail: Cameron@cen4ard.com

Rec date: Sep 22, 2016; Acc date: Oct 04, 2016; Pub date: Oct 06, 2016

Copyright: (C) 2016 Camp CJ, et al. This is an open-access article distributed under the terms of the Creative Commons Attribution License, which permits unrestricted use, distribution, and reproduction in any medium, provided the original author and source are credited.

\section{Short Communication}

While persons with dementia benefit from listening to music, there has been little research on teaching persons with dementia to play musical instruments, nor on the resulting effects of such teaching on these persons and their caregivers. Given that procedural learning systems are available to persons with mild to moderate dementia [1-3], we developed and initially assessed a music program (MusicMuse ${ }^{\mathrm{rut}}$ ) involving Orff instruments (e.g., metallophones), making music through striking instruments with mallets. This decision was based on the capacity of persons with Alzheimer's disease and related disorders to have motor learning and priming (learning through practice) available, even when memory for recent events and episodes is impaired.

Using external cues (e.g., color coding of bars to be struck), errorless learning (e.g., removing bars not being used), motor learning, priming, and other techniques from music education and neuropsychological rehabilitation [4-6], we taught persons with dementia in an assisted living residence to play components of songs such that, as an ensemble, these compositions were presented songs in a "concert" format. Participants initially were assessed to determine their capacity to hold mallets, strike single notes, strike alternating notes, play multiple notes, etc. and then participants were provided practice with the component of songs which best matched their capacities. Afterwards, the participants practiced in an ensemble format.

The activity was highly and positively engaging for persons with dementia as well as for their caregivers. Increased self-esteem and selfconfidence in persons with dementia also were obtained. Afterwards, residents at this community learned the music to accompany a song sung by grade school students. This intergenerational activity was greatly enjoyed by both residents and students. Interestingly, some residents remembered the words and melody of the song as sung by the students at another music program session one month later. Many other incidents involving demonstration of memory for taking part in the program, such as recognition of instructors, also were observed. Residents also complimented each other on their performances and spontaneously assisted each other at times.

There are several take away messages from this program. First, persons with dementia can learn new behaviors if provided the opportunity to utilize memory and learning systems (such as procedural memory) still available and when training techniques adapted from rehabilitation and other educational systems based on these preserved abilities are utilized. This has enormous implications for the use of nonpharmacological interventions in persons with dementia and related disorders.

Second, persons with dementia are persons-normal individuals with cognitive impairments. This means that interest in learning new things, in creative arts, and a willingness to stretch the mind are still present in these persons if allowed the opportunity to express themselves.

Finally, this program also was created with the specific intent to refute the negative stereotypes associated with dementia: persons with dementia cannot learn; persons with dementia continually devolve and lose their personhood; persons with dementia are "victims" who are continually "suffering;" persons with dementia cannot be helped, merely shown patience while we wait for a cure. Watching the joy on the faces of participants as they acquired new skills, gained in confidence, and began forming relationships with their teachers and each other eloquently refutes these negative images.

\section{References}

1. Mast BT, Shouse J, Camp CJ (2015) Person-centered assessment and intervention for people with dementia. APA Handbook of clinical geropsychology 2: 319-339.

2. Camp CJ, Skrajner MJ, Lee MM, Judge KS (2010) Cognitive assessment in late stage dementia. Handbook of assessment in clinical gerontology. (2ndedn), John Wiley \& Sons, New York.

3. Camp CJ (1999) Memory interventions for normal and pathological older adults. Annual review of gerontology and geriatrics, Springer, New York.

4. Skrajner MJ, Haberman JL, Camp CJ, Tusick M, Frentiu C, et al. (2014). Effects of using nursing home residents to serve as group activity leaders: Lessons learned from the RAP Project. Dementia, 13(2), 274-285.

5. Camp CJ (2013) The Montessori approach to dementia care. Australian Journal of Dementia Care 2: 10-11.

6. Bourgeois M, Camp C, Rose M, White B, Malone M, et al. (2003) A comparison of training strategies to enhance use of external aids by persons with dementia. J Commun Disord 36: 361-379. 